\title{
Mumps in young adults: the canary in the coal mine
}

$\mathrm{T}$ o many people, mumps belongs to a bygone era of childhood diseases that are now prevented by immunization. But mumps is once more on the move, with recent outbreaks in many industrialized countries involving mainly older youth and young adults (aged $15-26$ years), many of whom are students. In Canada, an outbreak began earlier this year in Nova Scotia (see page 137). More than 370 cases have been reported there, and the number is still rising. The outbreak has spread to other Atlantic provinces, Ontario, Alberta and British Columbia. Outbreaks have also been reported in the United Kingdom ( $>50000$ cases in 2004/05), the United States ( $>2500$ cases in 2006) and Spain (> I300 in 2006/07), and previously in Alberta (> I80 cases in 2002) and Nova Scotia ( $>30$ cases in $\left.2005 / 06^{1}\right)$. In most cases the patient had received at least I dose of measles-mumps-rubella (MMR) vaccine as a child, and in the 2006 outbreak in the United States $46 \%$ had received 2 doses. The mumps paramyxovirus strains in the United States and Nova Scotia are similar to the G genotype from the United Kingdom, which spread widely.

Given that there is no effective antiviral agent for the prevention or treatment of mumps, the only recourse is prevention by means of immunization and controlling the spread through isolation during the infectious period. However, providing a booster "vaccine net" around the outbreak is logistically difficult given the diversity of the population of older youth and young adults. Likewise, isolation is fraught with difficulty judging by the recent Nova Scotia experience. Many young adults were potentially exposed to mumps while celebrating St. Patrick's Day at packed bars. Telling them to self-isolate when they had no symptoms was an exercise in futility. Another reason young adults are an ideal population for mumps outbreaks is that they tend to share close living quarters and have many more close contacts than older adults or children.

Compounding the risk of mumps in this age group is the fact that many young adults have had only I dose of MMR vaccine. Although a single dose of vaccine is $80 \%$ effective, this still leaves $20 \%$ of those immunized vulnerable. Even with 2 doses, up to $5 \%$ may still not be immune. Furthermore, prior immunization may result in more subclinical disease, which increases the potential for spread. Young adults with mumps who are feeling well may not seek medical assessment, and even if they do, physicians unfamiliar with mumps may miss the diagnosis. The consequences can be dire. Up to $38 \%$ of postpubertal men with mumps will experience orchitis, and about $13 \%$ will have reduced fertility. In addition, meningoencephalitis occurs at a rate of about 250 per 100000 cases, with a mortality of about $2 \%{ }^{2}$

\section{What can be done?}

Health care workers need to be more vigilant in quickly identifying cases of mumps so that the disease can be effectively contained. There also needs to be a means of rapidly disseminating information to both health care practitioners and the public about risks, symptoms and the need for isolation (see www.gov.ns.ca/hpp/mumps/health-professionals .html and www.gov.ns.ca/hpp/mumps/assessments.html).

In addition, the size of the population of older youth and young adults at risk in Canada needs to be reduced with a second dose of MMR vaccine. Multiple strategies can be used to accomplish this, such as a provincial catch-up program for those who leave school, the requirement of 2 doses of MMR vaccine before enrolment at college or university, and the development of creative approaches for catch-up programs for older youth who are not in school and young adults, possibly through programs in the workplace or in places where these groups congregate. Given the size and complexity of these necessary catch-up initiatives, federal funding is essential.

The current mumps outbreak in Canada has once again demonstrated the need for a national immunization registry so that provinces and territories can assess rapidly who is and who is not at risk.

Learning to control mumps outbreaks more effectively in this population offers an important opportunity for studying rapid education methods, innovative contact notification and isolation procedures, and creative measures to rapidly immunize mobile, at-risk young people. In addition, these mumps outbreaks are like the proverbial canary in the coal mine, warning us of the inadequacies in our present approach to infectious disease control. Older youth and young adults have been one of the groups largely affected by severe disease and the spread of other virologically related pandemic viral diseases in the past, particularly influenza. We have much to learn in general about controlling the spread of serious respiratory viral infections in this population. These mumps outbreaks are a good place to do that learning.

\section{Noni MacDonald MD}

Section Editor, Public Health, CMAJ

Ken Flegel MDCM

Senior Associate Editor, $C M A J$

For the Editorial-Writing Team (Paul C. Hébert, Matthew Stanbrook, Barbara Sibbald and Amir Attaran)

\section{REFERENCES}

I. Watson-Creed G, Saunders A, Scott J, et al. Two successive outbreaks of mumps in Nova Scotia among vaccinated adolescents and young adults. CMAJ 2006;175:483-8. 2. Caplan CE. Mumps in the era of vaccines. CMAJ I999;160:865-6. 